\title{
The effect of Friction Stir Processing on the fatigue life of MIG-Laser hybrid welded joints as compared to conventional FSW 6082-T6 aluminium joints
}

\author{
A. Els-Botes, D. G. Hattingh \& K. V. Mjali \\ Department of Mechanical Engineering, \\ Nelson Mandela Metropolitan University, South Africa
}

\begin{abstract}
From previous research, Friction Stir Processing (FSP) was identified as a unique processing method that could be applied to improve the microstructure of welded non-ferrous alloys. FSP is similar to Friction Stir Welding (FSW) in that the material is processed below the melting point of the material, but the emphasis is not to produce a joint as in the case of FSW, but to improve mechanical performance. The difference between the two processes is that FSP is used to improve an existing weld's mechanical properties through microstructure refinement. This investigation was conducted on an aluminium alloy due to the relative difficulty with which defect free welds can be produced using conventional fusion welding processes. The aluminium alloy sections were joined using a MIG-laser hybrid process with varying gap widths between the adjoining plates. Similarly, a number of plates were also prepared using a conventional FSW process for comparative purposes. After fabrication, samples were sectioned from the welded plates for mechanical testing in order to evaluate the integrity of the welds. Mechanical properties were evaluated by tensile, fatigue and microhardness testing. Based on comparative results between the FSP MIG-laser hybrid (FSPMLH), the MIG-laser hybrid (MLH) and FSW for the three different gap widths evaluated, several general trends could be observed: weld efficiency (based on tensile strength) was the highest for the 0mm gap MIG-laser hybrid welded plates; FSP had a negligible effect on the tensile strength of the MIG-laser hybrid welded plates, but the percentage elongation values increased significantly. The effect of FSP on fatigue life became more noticeable as the width of the gap between adjoining plates increased. Microstructure evaluation revealed that FSP resulted in a refinement of the as-welded dendritic structure as well as eliminating porosity in the weld. Keywords: friction stir processing, friction stir welding, fatigue testing, weld integrity, aluminium alloy, MIG-laser hybrid welding.
\end{abstract}




\section{Introduction}

Friction Stir Processing (FSP) is closely related to Friction Stir Welding (FSW). The original process development concentrated on the FSW process, which was developed by TWI (UK) in the early 1990s. The basic principle of FSW involves a non-consumable rotating weld tool, which generates frictional heat and plasticizes the weld location, leading to the formation of a joint while the material is in the semi-solid state. The main characteristics of such a joint are low distortion, the absence of melt-related defects and improved joint strength (even in alloys considered non-weldable by conventional fusion welding processes) [1]. The main purpose of FSP on the other hand is to modify the microstructure/profile of either an existing weld or solid material. FSP are done to induce superplasticity, casting modification (FTMP - friction thermomechanical processing) and processing for low temperature formability to name but a few documented processes. The importance of studying FSP as a possible industrial process has been driven by the recent emphasis on the development of ultrafine and nanocrystalline microstructures through severe plastic deformation (SPD). FSP involves SPD, but under conditions that include rapid transients and steep strain gradients and temperature [2]. A good understanding of the process and the associated microstructure evolution is required in order to develop FSP into a viable production process/stage.

\section{Material and processing parameters}

\subsection{Material}

The material used for this study was 6082-T6 aluminium alloy plate of $6 \mathrm{~mm}$ thickness. This is a heat treatable alloy which shows improved mechanical properties in the heat treated/aged condition due to the formation of beta double prime $\left(\mathrm{Mg}_{5} \mathrm{Si}_{6}\right)$ particles in the matrix [1]. The typical chemical composition and various properties of the parent plate are given in Table 1.

Table 1: $\quad$ Material properties: 6082-T6 aluminium alloy.

\begin{tabular}{|c|l|l|l|l|l|l|l|l|l|}
\hline Element & Al & Cr & Cu & Fe & Mg & Mn & Si & Ti & \multicolumn{1}{|c|}{$\mathbf{Z n}$} \\
\hline \multirow{2}{*}{ Wt \% } & $95.2-$ & 0,25 & 0,1 & 0,5 & $0,6-$ & $0,4-$ & $0,7-$ & 0,1 & 0,2 \\
& 98.3 & $\max$ & $\max$ & $\max$ & 1,2 & 1,0 & 1,3 & $\max$ & $\max$ \\
\hline \multicolumn{3}{|c|}{ Tensile strength: } \\
310MPa & \multicolumn{3}{c|}{ Yield strength: } & \multicolumn{3}{c|}{ Melting point: $660^{\circ} \mathrm{C}$} \\
\hline
\end{tabular}

\subsection{MIG-Laser hybrid weld parameters}

MIG-laser hybrid (MLH) welded plates were produced by the National Laser Centre (SA) using the settings as given in Table 2. AWS ER 4043 filler wire was used during the welding process and the shielding gas was at a constant flow of $22 \mathrm{l} / \mathrm{min}$ for all the welds. 
Table 2: $\quad$ MIG-laser hybrid welding parameters.

\begin{tabular}{|c|c|c|c|c|}
\hline Power, kW & Welding speed, $\mathbf{m m} / \mathbf{m i n}$ & Current, $\mathbf{A}$ & Voltage, $\mathbf{V}$ & Gap width, $\mathbf{m m}$ \\
\hline 4 & 2000 & 170 & 21 & 0 \\
\hline 4 & 2000 & 180 & 21 & 0,5 \\
\hline 3 & 1500 & 180 & 21 & 1 \\
\hline
\end{tabular}

Table 3: Energy values associated with the MIG-laser hybrid welding process.

\begin{tabular}{|c|c|c|c|}
\hline Power, $\mathbf{k W}$ & $\begin{array}{c}\text { Line Energy }- \text { Laser, } \\
\mathbf{k J} / \mathbf{m}\end{array}$ & $\begin{array}{c}\text { Heat input }- \text { MIG, } \\
\mathbf{k J} / \mathbf{m}\end{array}$ & Gap width, $\mathbf{m m}$ \\
\hline 4 & 2 & 96,4 & 0 \\
\hline 4 & 2 & 102,1 & 0,5 \\
\hline 3 & 2 & 136,1 & 1 \\
\hline
\end{tabular}

The energy associated with the MIG-laser hybrid weld can be divided into the two processes i.e. laser weld and MIG weld. For the laser weld part the associated line energy can be calculated using the following equation:

$$
\mathrm{E}_{1}=\frac{\mathrm{P}}{\mathrm{v}}
$$

where:

$\mathrm{E}_{1}=$ Line energy $(\mathrm{J} / \mathrm{m}), \mathrm{P}=$ laser power $(\mathrm{W})$ and $\mathrm{v}=$ welding speed $(\mathrm{m} / \mathrm{min})$.

Heat input for the MIG part of the hybrid weld was calculated using the following general formula:

$$
Q=\left(\frac{V . I .60}{s .1000}(\text { efficiency })\right)
$$

where: $\mathrm{Q}=$ heat input $(\mathrm{kJ} / \mathrm{mm}), \mathrm{V}=$ Voltage, $\mathrm{I}=$ Current, $\mathrm{s}=$ welding speed $(\mathrm{mm} / \mathrm{min})$ and efficiency $=0,9$ for MIG processes.

The resulting energy values for the two parts of the hybrid welding process are given in Table 3. From this data it is evident that the main source of heat input was the MIG process.

It has been determined from previous studies that in order to obtain a weld of acceptable quality there need to be an increase in heat input as the gap width between plates increase.

\subsection{Friction Stir Processing (FSP)}

The tool designed for the FSP procedure differ from conventional FSW tools in that the emphasis for this application is to improve the weld microstructure and reduce stress concentration at the weld root bead. The main design difference relates to the smaller shoulder and pin geometry. Figure 1 shows the tool used for the FSP process. The tool was manufactured from H13 tool steel, which proved to be good quality material to use during the FSW of aluminium alloys. FSP was done using a rotational speed of 450rpm with a feed rate of $120 \mathrm{~mm} / \mathrm{min}$. As only partial penetration was needed, the pin length was considerably shorter than the plate thickness. 


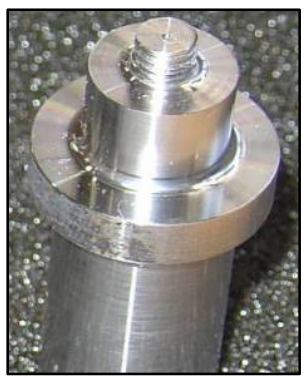

\section{Tool dimensions:}

Shoulder diameter $=15 \mathrm{~mm}$

Pin diameter $=6 \mathrm{~mm}$

Pin length $=3 \mathrm{~mm}$

Figure 1: $\quad$ Friction stir processing tool.

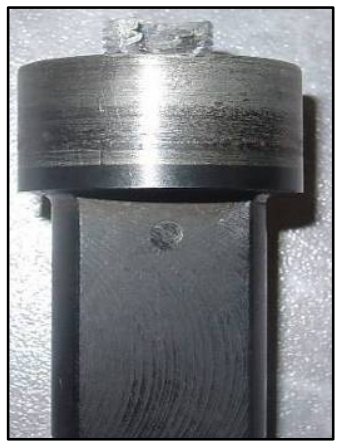

\section{Tool dimensions:}

Shoulder diameter $=25 \mathrm{~mm}$

Pin diameter $=10 \mathrm{~mm}$

Pin length $=5,8 \mathrm{~mm}$

Figure 2: $\quad$ Friction stir welding tool.

\subsection{Friction stir welding}

The FSW tool used to join the aluminium alloy plates have been designed to weld $6 \mathrm{~mm}$ thick plate successfully. The pin consists of a threaded profile with on flute running parallel to the pin on one side. The flute improves the flow path of material during welding and also assists in the mixing of material of the plates being welded. The tool appearance as well as dimensions is given in Figure 2. The process used a rotational speed of $500 \mathrm{rpm}$ and a feed rate of $80 \mathrm{~mm} / \mathrm{min}$.

\subsection{Mechanical testing}

All samples for evaluation were removed from the stable region of the welded / processed plate. The stable region is defined as that region where the process variables, mainly temperature are stable, see Figure 3.

Fatigue and tensile samples were machined to dimensions according to ASTM E466 and E8 respectively. Fatigue samples were tested in the polished condition. 


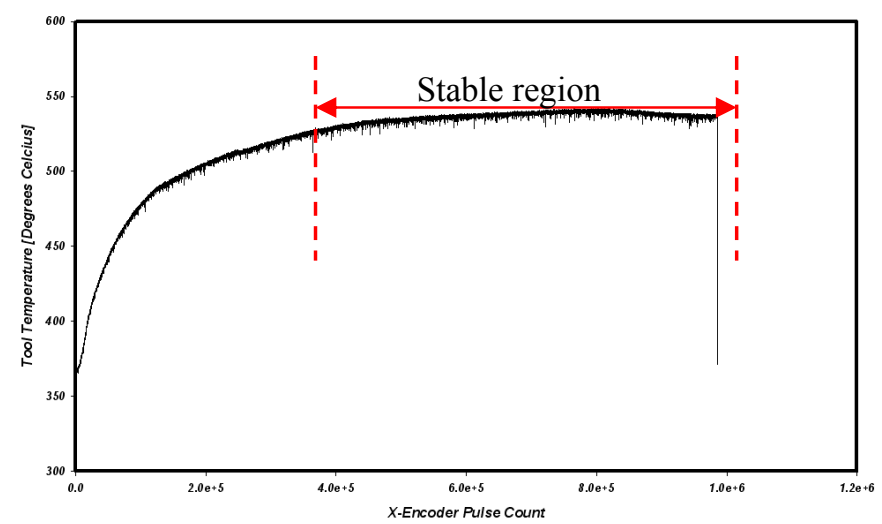

Figure 3: Temperature profile showing the stable temperature region.

Table 4: $\quad$ Average tensile results.

\begin{tabular}{|c|c|c|c|c|c|}
\hline Process & $\begin{array}{c}\text { Gap } \\
\text { width, } \mathbf{m m}\end{array}$ & $\begin{array}{c}\mathbf{0 , 2} \% \text { Proof } \\
\text { stress, MPa }\end{array}$ & $\begin{array}{c}\text { Tensile strength, } \\
\text { MPa }\end{array}$ & $\begin{array}{c}\text { Elongation, } \\
\mathbf{\%}\end{array}$ & $\begin{array}{c}\text { Weld } \\
\text { Efficiency, } \\
\text { \% }\end{array}$ \\
\hline $\begin{array}{c}\text { Parent } \\
\text { plate }\end{array}$ & - & 294 & 326 & 14,1 & 100 \\
\hline \multirow{3}{*}{ MLH } & 0,0 & 190 & 247 & 3,2 & 76 \\
& 0,5 & 150 & 221 & 3,0 & 68 \\
\hline \multirow{3}{*}{ FSP } & 1,0 & 150 & 228 & 3,2 & 75 \\
& 0,0 & 153 & 237 & 6,4 & 73 \\
& 0,5 & 160 & 222 & 5,2 & 66 \\
FSW & 1,0 & 141 & 219 & 6,4 & 67 \\
& 0,0 & 140 & 223 & 7,2 & 68 \\
& 0,5 & 120 & 226 & 7,1 & 69 \\
\hline
\end{tabular}

\section{Results}

\subsection{Tensile tests}

The average tensile results of three specimens are given in Table 3 for the three processes and three gap width variations. Weld efficiency (WE) is measured by the relationship as shown by equation 3 .

$$
W E=\frac{U T S_{\text {weld }}}{U T S_{\text {original }}} x 100
$$

Measuring joint quality in terms of weld efficiency indicates that FSP did not lead to an improvement in the strength of the weld. However, the percentage elongation values indicate an increase in ductility of the weld (up to $50 \%$ increase). The area under the stress-strain curve also increased for the FSP samples which signify an increase in toughness of the weld. The conventional FSW samples showed the highest ductility and their strength values corresponded to those of the FSP samples. 


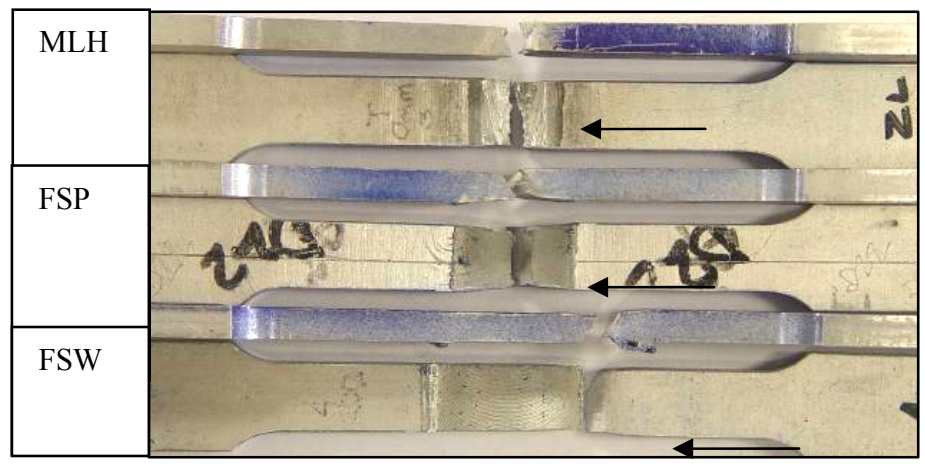

Figure 4: $\quad$ Fracture locations observed after tensile testing.

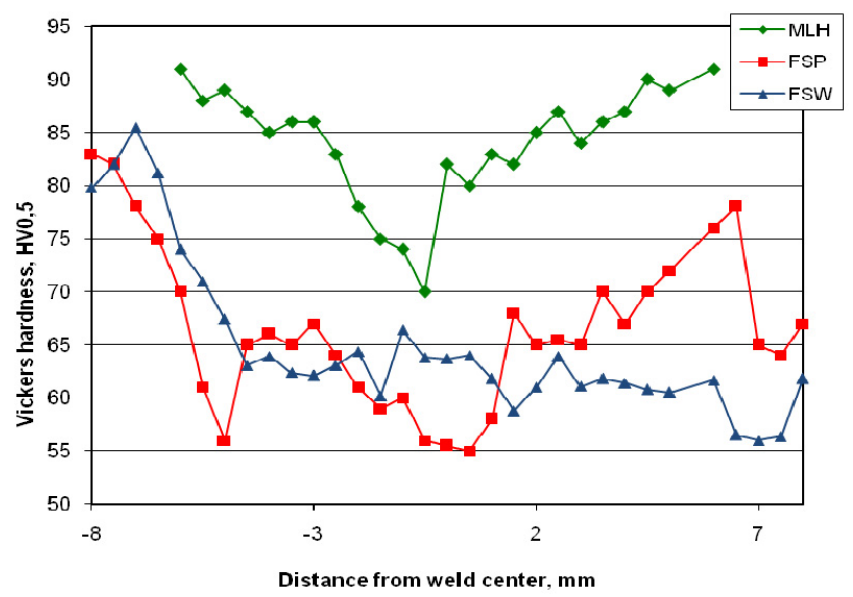

Figure 5: Vickers microhardness profiles of processed/weld regions.

The fracture location for the MLH and FSP samples corresponded to the centre of the sample whereas the fracture location of the FSW sample was observed to be in the heat affected zone (HAZ) of the sample. The fracture positions are indicated in Figure 4 by arrows.

\subsection{Vickers microhardness profiles}

Vickers microhardness measurements were taken at a distance of $3 \mathrm{~mm}$ below the weld root. The resultant hardness profiles are shown in Figure 5. From these profiles it is evident that the area with the lowest hardness corresponds to the tensile failure position. For the FSP and MLH samples the region of lowest hardness corresponds with approximately to the centre of the sample whereas the lowest hardness for the FSW samples was observed in the HAZ.

Since there is a direct relationship between hardness and strength, failure during tensile loading conditions can be expected in these regions. FSP and FSW samples indicate lower hardness values than the MLH samples. 


\subsection{Fatigue tests}

Single load fatigue tests were conducted for comparative studies. After preliminary testing, a stress amplitude of $170 \mathrm{MPa}$ was chosen with $\mathrm{R}=0,1$ and a frequency of $40 \mathrm{~Hz}$. Five samples were tested for each process and gap width. The results of comparative fatigue testing are given in Table 4 .

\subsection{Fracture surface analysis}

The fracture positions observed during fatigue testing are shown in Figure 6 . The MLH and FSP samples' fracture path approximately followed the centre of the weld whereas the FSW samples failed in the HAZ of the material similar to the fracture positions observed during tensile testing.

Evaluation of the fracture surfaces revealed that for the FSP samples, fracture initiated on the MLH side of the weld with final fracture on the FSP side.

Further evaluation revealed that there is quite a large number of gas porosity as well as shrinkage porosity present in the MLH weld. Other defects observed include inclusions which were rich in iron and from analysis these inclusions can be classified as iron oxide particles in the weld. Fracture surface appearance of the MLH samples are shown in Figure 7.

The FSP samples showed similar defects on the MLH side of the specimen with a fine granular fracture appearance on the FSP side. Only void type defects were observed on the FSP side of the weld. These void types of defects did not

Table 5: $\quad$ Single load (170MPa) fatigue results.

\begin{tabular}{|c|c|c|}
\hline Process & Gap width, $\mathbf{m m}$ & Average cycles to failure \\
\hline \multirow{3}{*}{ MLH } & 0 & 181908 \\
& 0,5 & 106349 \\
& 1,0 & 136731 \\
\hline \multirow{2}{*}{ FSP } & 0 & 150750 \\
& 0,5 & 253645 \\
\multirow{3}{*}{ FSW } & 1,0 & 243555 \\
& 0 & 295358 \\
& 0,5 & 202376 \\
& 1,0 & 175445 \\
\hline
\end{tabular}

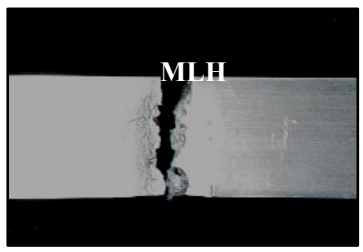

Figure 6
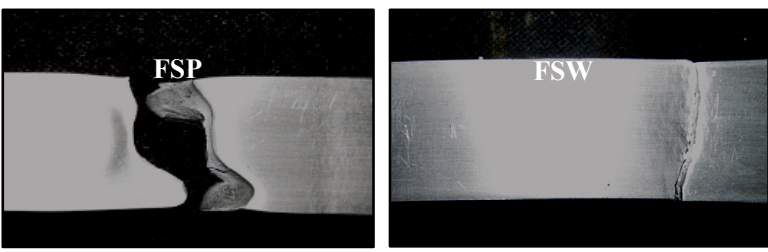

Fracture positions of fatigue samples. 


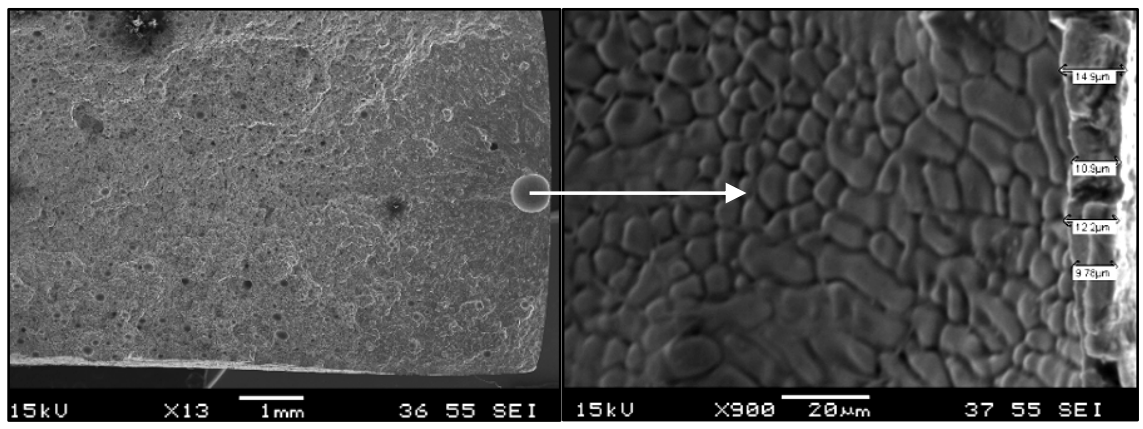

Figure 7: Fracture surface appearance in fatigue zone of MLH welded samples.

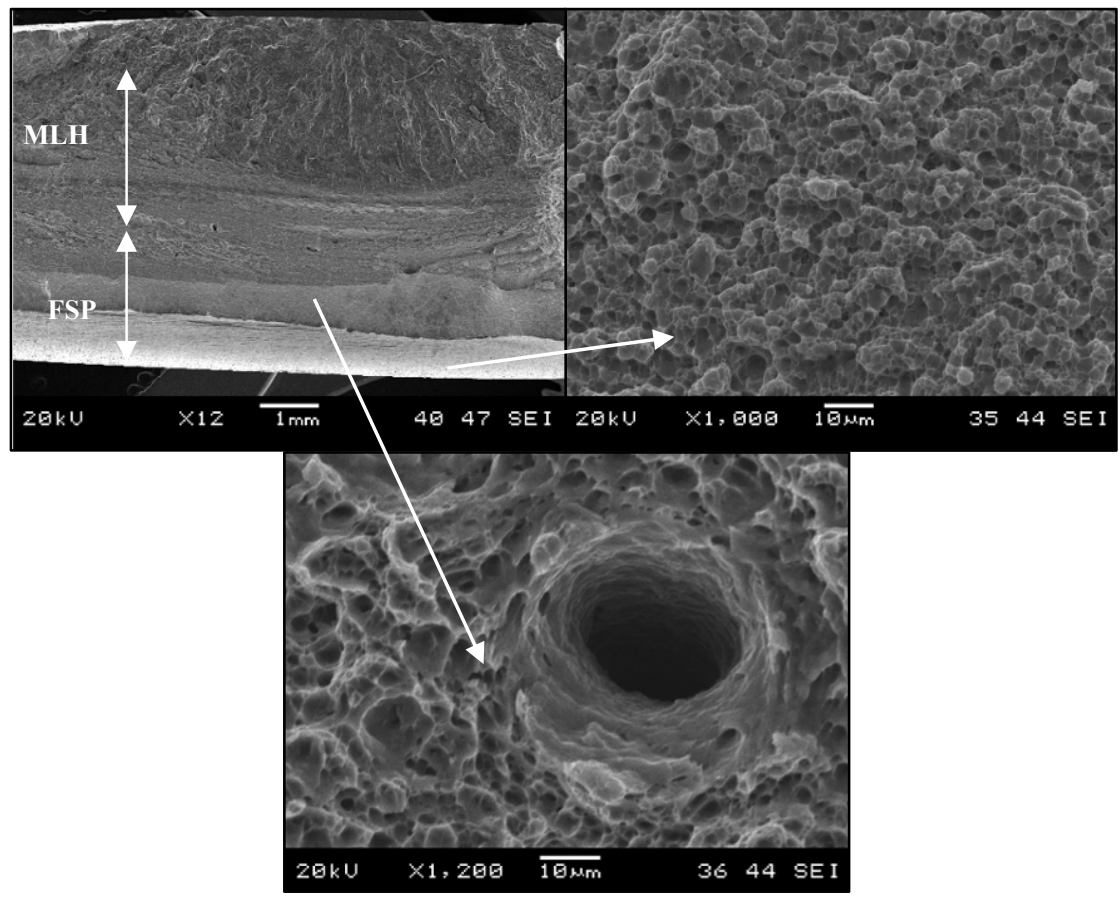

Figure 8: $\quad$ Fracture surface appearance in fatigue zone of FSP samples.

contribute to crack initiation. Figure 8 shows the typical fracture surface appearance of a FSP sample. The defects observed on the FSP side correspond to defects documented by other researches studying FSW of aluminium alloys [3].

The fracture surface appearance of the FSW samples showed a typical smooth featureless surface resembling the Friction Processed section as shown in Figure 8 . 


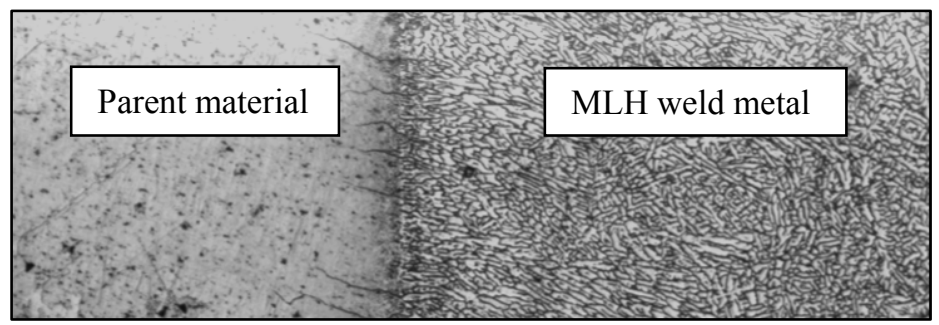

Figure 9: $\quad$ MLH weld zone microstructure (x100).
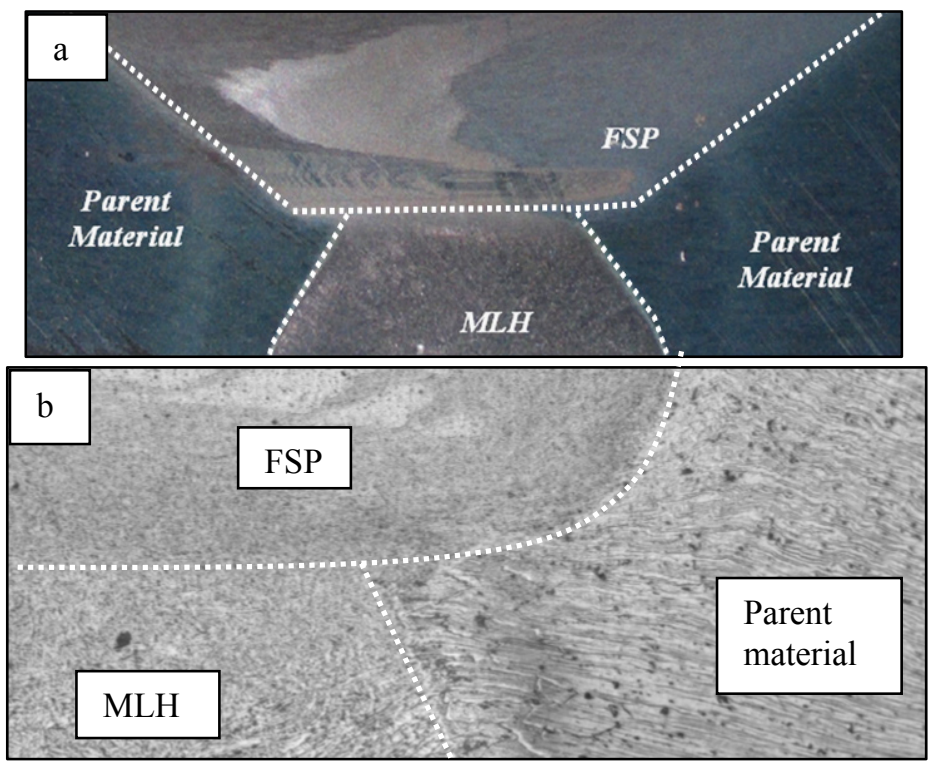

Figure 10: Appearance of friction stir processed (FSP) sample: (a) macro; and (b) microscopic appearance showing the various zones observed (x100)

\subsection{Microstructure}

The microstructure in the region of the fusion line of the MHL welded samples are shown in Figure 9. The weld metal shows a typical dendritic structure with a narrow heat affected zone adjacent to the fusion line.

The FSP samples exhibited various zones which are directly associated with the procedure / process experienced by the sample. The various zones observed are shown in Figure 10(a) and (b).

The samples joined by the FSW process exhibited a microstructure similar to that observed on the FSP side of the sample as shown in Figure 10. 


\section{Discussion and conclusions}

Friction Stir Processing is as a complex process as the FSW process. Tool design and selection of process parameters is of critical importance as it influences the maximum temperature reached by the stirred zone and as a consequence influence the resultant modified zone's properties. Process parameter selection is different to that of the FSW process in that the aim of the process is not to create a joint but to refine the microstructure in a specific region. From the results obtained the following general conclusions can be made:

- Friction stir processing of the MIG-laser hybrid welded samples did not lead to an increase in static strength (tensile and yield),

- FSP of the surface of the MLH samples did lead to an increase in weld ductility and toughness of the samples as observed from tensile testing,

- Fracture position of tensile and fatigue samples were the same i.e. in the centre for FSP and MLH samples and in the HAZ for the FSW samples. This fracture location coincided with the region of lowest hardness of the samples,

- Fatigue testing revealed that FSP of MIG-laser hybrid samples lead to an increased number of cycles to failure for the $0,5 \mathrm{~mm}$ and $1,0 \mathrm{~mm}$ gap width samples,

- Fatigue fracture initiation started on the MLH side of the friction stir processed samples,

- Fatigue fracture initiation of the MLH samples coincided with near surface gas porosity and / or inclusions in the weld metal,

- Friction stir processing refined the MLH weld metal and HAZ microstructure and eliminated gas and shrinkage porosity that were formed during the MIG-laser welding process

\section{Acknowledgements}

We would like to acknowledge the following:

- The National Laser Centre of South Africa for producing MIG-laser hybrid welded samples.

- The National Research Foundation (South Africa) for project funding.

- The Light Metals Initiative (LMI) for bursary funding.

- Dr T Paterson for technical advice.

\section{References}

[1] Khaled, T., An outsider look at friction stir welding, Federal Aviation Administration (FAA), Report \# ANM-112N-05-06, pp.7-15, 2005. 
[2] McNelly, T.R., et al., Recrystallization mechanisms during friction stir welding/processing of aluminium alloys. Scripta Materialia, 58, pp. 349354, 2008.

[3] James, MN., Hattingh, DG. \& Bradley, GR., Weld tool travel speed effects on fatigue life of friction stir welds in 5083 aluminium. International Journal of Fatigue, 25, pp1389-1398, 2003. 